\title{
AVALIAÇÃO DO DESEMPENHO PRODUTIVO DE LINHAGENS DE TILÁPIA DO NILO (Oreochromis niloticus) EM MARINGÁ-PR
}

\section{Evaluation of the Productive Performance of Strain of Tilapia of the Nile (Oreochromis niloticus) in Maringa-PR}

\author{
Vanessa Petronilo Vieira ${ }^{1}$ \\ Ricardo Pereira Ribeiro ${ }^{2}$ \\ Héden Luiz Marques Moreira ${ }^{3}$ \\ Jayme Aparecido Povh ${ }^{4}$ \\ Lauro Vargas ${ }^{5}$ \\ Nelson Mauricio Lopera Barrero ${ }^{6}$
}

\section{Resumo}

O objetivo deste trabalho foi verificar o desempenho de crescimento de diferentes linhagens de tilápia do Nilo (O. niloticus), na fase inicial em caixas d'água e na fase final em viveiros de terra e em tanques de concreto. Foram estudadas as linhagens Chitralada (UEM/CODAPAR), Supreme, proveniente da Piscicultura Aquabel, Bouaké (UEM/CODAPAR) e Chitralada (Aquabel). $O$ peso final para primeira fase do experimento foi de 59,14 g, 65,74 g, 48,70 g e 58,40 g, respectivamente às espécies acima citadas. Na segunda fase, o peso final foi de 306,82 g, 344,74 g, 263,49 g e 340,50 g e rendimento de filé de 30,3\%, 30,6\%, 32,9\% e 30,8\%, para mesma ordem anterior. A linhagem Supreme apresentou melhor crescimento nas duas fases do experimento. Palavras-chave: Oreochromis nitloticus; Tilápia do Nilo; Supreme.

\section{Abstract}

The objective of this research was to verify the growth performance of different Nile Tilápia's strains (O. niloticus), in the initial phase inside the water boxes and in the final phase inside the concrete fishpond and in land tanks. The strains studies were on Chitralada and Supreme proceeded from the Aquabel fish culture, and Bouake and Chitralada strains proceeded from the station of the Universidade Estadual de Maringá fish culture - UEM/CODAPAR. In the first phase, the final weight of the experiment was $59.14 \mathrm{~g}, 65.74 \mathrm{~g}, 48.70$ $\mathrm{g}$, and $58.40 \mathrm{~g}$ respectively. In the second phase, the final weight was $306.82 \mathrm{~g}, 344.74 \mathrm{~g}, 263.49 \mathrm{~g}$, and $340.50 \mathrm{~g}$. The filet income was $30.3 \%, 30.6 \%, 32.9 \%$, and $30.8 \%$ for the same previous order. The Supreme strain presented better growth in the two phases of the experiment

Keywords: Oreochromis nitloticus; Nile Tilápia; Supreme.

\footnotetext{
${ }^{1}$ Zootecnista, Mestre em Zootecnia.

2 Zootecnista, Professor Adjunto do Departamento de Zootecnia da Universidade Estadual de Maringá (rpribeiro@uem.br).

${ }^{3}$ Engenheiro Agrônomo - Professor Adjunto do Departamento de Biologia Molecular da Universidade Federal de Pelotas.

${ }^{4}$ Zootecnista, Doutorando em Zootecnia na Universidade Estadual de Maringá.

${ }^{5}$ Médico Veterinário, Professor Associado do Departamento de Zootecnia da Universidade Estadual de Maringá (lvargas@uem.br).

${ }^{6}$ Médico Veterinário/Zootecnista, Doutorando em Zootecnia da Universidade Estadual de Maringá.
} 


\section{Introdução}

Há pelo menos 77 espécies descritas no gênero Tilápia (THYS, 1969). Jhnigran; Gopalahrisshnan (1974) listaram 22 espécies que foram utilizadas em experimentos ou na produção de peixe em escala comercial.

Tilápia é a denominação comum de grande gama de espécies de peixes ciclídeos, que, conforme Popma; Phelps (1998), distribuem-se originalmente do centro-sul da África até o norte da Síria. De acordo com Lovshin (1997), a distribuição das tilápias pelo mundo começou com intuito da criação de peixes para a subsistência em países em desenvolvimento. Entretanto, de acordo com Lazard (1984), a espécie O. niloticus demonstrou alto potencial para a aqüicultura em vários sistemas de criação. A primeira espécie introduzida em outros países foi a O. mossambicus, porém essa se mostrou de baixo desempenho para a aqüicultura (LAZARD; ROGNON, 1997).

Segundo Popma; Lovshin (1995), as tilápias de importância comercial estão divididas em três principais grupos taxonômicos, distintos basicamente pelo comportamento reprodutivo: as do gênero Tilapia spp. (incubam seus ovos em substratos), Oreochromis spp. (incubam os ovos na boca da fêmea) e Sarotherodon spp. (incubam os ovos na boca do macho ou de ambos).

A produção mundial de tilápias nos últimos anos foi influenciada fortemente pela rápida expansão da espécie Oreochromis niloticus cultivada na China, Filipinas, Tailândia, Indonésia e Egito. Entre 1984 e 1995, a produção mundial de tilápias, extrativista e cultivada, apresentou um acréscimo considerável, passando de 38\%, ou seja, $198.000 \mathrm{t}$, para 57\%, $659.000 \mathrm{t}$ (FITZSIMMONS, 2000).

No Brasil, a espécie que vem obtendo grande destaque é a tilápia do Nilo (Oreochromis niloticus), uma espécie precoce, que apresenta excelente desempenho em diferentes sistemas de criação (CYRINO et al., 1998).

A tilápia do Nilo, dentre as demais espécies de tilápias existentes, vem destacando-se por apresentar inúmeras qualidades zootécnicas, como rusticidade, crescimento rápido, grande adaptação alimentar, boa conversão alimentar e ganho de peso. Além disso, apresenta uma carne branca, de excelente paladar e textura, com espinhos ausentes na musculatura lateral, facilitando a técnica de filetagem e a industrialização da carcaça. Seu filé caracteriza-se pela presença de poucos espinhos e ausência daqueles em forma de "Y", não desejáveis pelo consumidor. Pode-se incluir ainda a utilização do uso de sua pele para o curtimento, que representa uma fonte a mais de renda para o piscicultor ou para a indústria de filés (TORLONI, 1984; SCHMDT, 1988; BOLL et al., 1995; HILSDORF, 1995).

No Brasil, estima-se uma produção piscícola anual ao redor de 60 mil toneladas/ano, sendo que destas o Paraná produz 17 mil toneladas/ ano (LOVSHIN; CYRINO,1997). Portanto, a produção da piscicultura brasileira representa menos de 10\% da produção da pesca brasileira, cerca de 700 mil toneladas/ano, enquanto o consumo nacional está próximo de um milhão de toneladas/ano.

Para aumentar a produção e atender esta demanda crescente é preciso desenvolver linhagens melhoradas. Uma estratégia de melhoramento genético para aumento da produção tem sido a hibridização entre espécies, contudo, este aumento não tem sido verificado. Um dos grandes entraves à aplicação da hibridização em tilápias foi a constatação de uma forte interação genótipo-ambiente verificada em um estudo onde se combinou oito linhagens de tilápias do Nilo (BENTSEN et al.,1998). Dada esta grande interação-genótipo ambiente, haveria a necessidade de uma enorme estrutura para produzir os cruzamentos específicos para cada ambiente.

Alternativa para o melhoramento genético seria o uso da seleção. Entretanto, programas de seleção em tilápias, como outras espécies aquáticas, têm sido difíceis de implementar, devido às formas juvenis serem tão pequenas para serem marcadas, que comparações de crescimento não podem ser feitas em ambientes comuns (HERBINGER et al., 1997). Isso também dificulta ou inviabiliza a manutenção de registros de pedigrees. Em face disso, a seleção pode ser praticada, mas requer muitos recursos físicos e financeiros para a obtenção de resultados satisfatórios.

\section{Material e métodos}

O experimento foi realizado na Estação Experimental de Piscicultura da Universidade Estadual de Maringá, UEM/CODAPAR, localizada no distrito de Floriano, município de Maringá-PR, no período de janeiro a setembro de 2003. 
Foram utilizadas quatro linhagens de tilápia: Chitralada (CHIA) (tailandesa), importada do ASIAN INSTITUT of TECHNOLOGY (AIT) da Tailândia em 1996, e o lançamento da GenoMar, a tilápia Supreme (SUP) importada da Noruega em 2002, ambas provenientes da Aquabel, comparadas com outras duas linhagens, Chitralada (CHIM) de $2^{\mathrm{a}}$ geração das importadas em 1996 e a Bouaké (BOKE) introduzida no Brasil em 1971, provenientes da Estação de Piscicultura UEM/CODAPAR.

O experimento foi divido em duas fases, sendo que na fase inicial os animais foram mantidos em 20 caixas d'água de 500 litros em estufa, cada caixa contendo 25 peixes, com cinco repetições por linhagem. A primeira fase do experimento teve início no dia 31 de janeiro de 2003.

A ração foi fornecida ad libitum, duas vezes ao dia, nas duas fases do experimento.

Durante a execução do projeto, realizouse o monitoramento da qualidade de água, sendo avaliado semanalmente $\mathrm{pH}$, condutividade, temperatura e oxigênio. Quinzenalmente foram monitorados os níveis de ortofosfato, amônia e nitrito pelo uso de espectofotômetro digital. A limpeza das caixas foi feita por sinfonagem uma vez por semana, com a finalidade de retirar o excesso de ração.

O encerramento desta fase foi realizado em maio de 2003, sendo que os animais permaneceram nesta fase por noventa e um dias. Para 0 encerramento desta fase, foi realizada a sedação dos animais para realização da biometria e marcação dos peixes com miçangas coloridas para o início da segunda fase do experimento.

Após os animais estarem devidamente marcados com fio de náilon e miçangas, esses foram transferidos para viveiros de terra e tanques de concretos; as transferências dos animais foram realizadas no mesmo dia do encerramento da primeira fase. Foram utilizados dois viveiros de terra, sendo que cada um recebeu 140 peixes, e cinco tanques de concreto, cada um com vinte animais.

Nesta fase, a temperatura da água e 0 oxigênio dissolvido na água foram monitorados diariamente.

O encerramento da segunda fase do experimento foi realizado no dia 19 de setembro de 2003; nesta fase, os animais permaneceram por 134 dias. Ao final foi avaliado o desempenho produtivo na fase de engorda, pelos parâmetros: comprimento total, comprimento padrão, peso vivo, rendimento do filé e peso do fígado para as quatro linhagens.

Foi utilizado delineamento inteiramente casualizado com quatro tratamentos e 5 repetições. Os dados foram interpretados por uma análise de variância, teste de Tukey a 5\% de probabilidade e utilizando-se o procedimento SAEG (1989).

O modelo matemático utilizado para a análise de variância foi:

$$
\begin{aligned}
& \mathrm{Y}_{\mathrm{ij}}=\mu+\mathrm{T}_{\mathrm{ij}}+\mathrm{e}_{\mathrm{ij}} \text { onde: } \\
& \mu=\text { média dos tratamentos } \\
& \mathrm{T}_{\mathrm{k}}=\text { efeito do tratamento } \mathrm{i} \text {, variando de } 1 \text { a } 4 \\
& \mathrm{e}_{\mathrm{ij}}=\text { erro aleatório }
\end{aligned}
$$

\section{Resultados e discussão}

Durante o experimento, todos os parâmetros de qualidade de água avaliados apresentaram-se dentro da normalidade.

Na primeira fase do experimento, observou-se (Tabela 1) que a linhagem Bouaké iniciou o experimento com peso inicial significativamente $(\mathrm{P}>0,05)$ maior que as demais, mas terminou a primeira fase com o menor peso final, resultando no menor ganho de peso, sendo que a linhagem Supreme obteve o maior ganho de peso final, comprimento total e comprimento padrão. 
Tabela 1 - Valores médios para as variáveis de desempenho de peixes das diferentes linhagens de tilápia do Nilo, Oreochromis niloticus, na primeira fase do experimento, de 15 dias a 91 dias de cultivo.

Table 1 - Average values for the fish performance variables of different Nile tilapia's strains, Oreochromis niloticus, in the first phase of the experiment, between 15 and 91 days of culture.

\begin{tabular}{|l|l|l|l|l|l|l|l|}
\hline & $\begin{array}{l}\text { Comp. } \\
\text { Padrão } \\
\text { Inicial } \\
\text { (cm) }\end{array}$ & $\begin{array}{l}\text { Comp. } \\
\text { Total } \\
\text { Inicial } \\
\mathbf{( c m )}\end{array}$ & $\begin{array}{l}\text { Peso } \\
\text { Inicial } \\
\mathbf{( g )}\end{array}$ & $\begin{array}{l}\text { Comp. } \\
\text { Padrão } \\
\text { Final } \\
\mathbf{( c m )}\end{array}$ & $\begin{array}{l}\text { Comp. } \\
\text { Total } \\
\text { Final } \\
\text { (cm) }\end{array}$ & $\begin{array}{l}\text { Peso } \\
\text { Final } \\
\text { (g) }\end{array}$ & $\begin{array}{l}\text { Ganho } \\
\text { de Peso } \\
\text { (cm) }\end{array}$ \\
\hline CHIM & 3,240 & 4,109 & 1,050 & $11,56 \mathrm{ab}$ & 13,92 & 59,14 & $58,09 \mathrm{ab}$ \\
SUP & 3,644 & 4,628 & 1,386 & $12,12 \mathrm{a}$ & 14,86 & 65,74 & $64,35 \mathrm{a}$ \\
BOKE & 3,632 & 4,412 & 1,464 & $10,90 \mathrm{~b}$ & 13,14 & 48,70 & $47,23 \mathrm{~b}$ \\
CHIA & 2,900 & 4,072 & 0,974 & $11,84 \mathrm{ab}$ & 14,38 & 58,40 & $57,42 \mathrm{ab}$ \\
\hline
\end{tabular}

* CHIM= Chitralada CODAPAR, SUP= Supreme, BOKE= Bouaké, CHIA= Chitralada Aquabel

Wagner (2002), em estudo com as linhagens Chitralada e Bouaké, encontrou diferenças significativas $(\mathrm{P}>0,05)$ em peso médio final, sendo a linhagem Chitralada superior; o mesmo ocorreu para comprimento total e comprimento padrão. Estes resultados se assemelham ao encontrado por Boscolo et al. (1999), trabalhando com as duas linhagens na fase inicial de criação.

Dessa forma, a linhagem Supreme e a Chitralada mostraram-se mais eficientes, comprovando uma possível melhora genética destas linhagens, quando comparadas à linhagem Bouaké.

Não houve diferenças significativas $(\mathrm{P}>0,05)$ entre as linhagens para os parâmetros comprimento padrão e peso do filé. Para o parâmetro comprimento total, a linhagem Bouaké apresentou o menor comprimento, sendo significativamente $(\mathrm{P}>0,05)$ menor que as demais.

O maior peso final foi obtido pela linhagem Supreme, que foi significativamente su- perior $(\mathrm{P}>0,05)$ à linhagem Bouaké, mas não foi superior estatisticamente em relação à Chitralada. Ao comparar-se linhagem Chitralada com a linhagem Bouaké, apenas a linhagem proveniente da empresa Aquabel foi significativamente superior.

Na segunda fase do experimento, o maior peso final foi obtido pela linhagem Supreme (Tabela 2) e o menor pela linhagem Boauké, mesmo resultado da primeira fase do experimento. Não houve diferença significativa entre peso final da linhagem Bouaké e Chitralada UEM/CODAPAR, diferindo significativamente apenas da linhagem Supreme e Chitralada Aquabel. A diferença entre a linhagem Chitralada Aquabel e Chitralada UEM/ CODAPAR pode ser explicada pelas condiç̧ões de criação, pois as da Empresa Aquabel são mantidas em ambientes controlados e manejos constantes, o que confere aos lotes da empresa uma maior uniformidade. 
Tabela 2 - Valores médios para variáveis de desempenho de peixes, mantidos em viveiro de terra, das diferentes linhagens de tilápia do Nilo (Oreochromis niloticus), na segunda fase do experimento, de 91 dias a 134 dias de cultivo.

Table 2 - Average values for fish performanœe variables, kept in land fishery, of the different Nile tilapia's strains (Oreochromis niloticus), in the second phase of the experiment, between 91 and 134 days of culture.

\begin{tabular}{|l|l|l|c|c|}
\hline & $\begin{array}{c}\text { Comp. padrão } \\
\text { cm }\end{array}$ & $\begin{array}{c}\text { Comp. Total } \\
\text { cm }\end{array}$ & $\begin{array}{c}\text { Peso } \\
\mathbf{g}\end{array}$ & $\begin{array}{c}\text { Peso do filé } \\
\mathbf{g}\end{array}$ \\
\hline CHIM & 20,41 & $27,10^{\mathrm{a}}$ & $306,82 \mathrm{ab}$ & 92,98 \\
SUP & 20,84 & $25,72 \mathrm{a}$ & $344,73 \mathrm{a}$ & 105,49 \\
BOKE & 18,97 & $23,13 \mathrm{~b}$ & $263,49 \mathrm{~b}$ & 86,88 \\
CHIA & 21,45 & $25,98 \mathrm{a}$ & $340,50 \mathrm{a}$ & 104,93 \\
\hline
\end{tabular}

${ }^{*} \mathrm{CHIM}=$ Chitralada CODAPAR, SUP= Supreme, BOKE= Bouaké, $\mathrm{CHIA}=$ Chitralada Aquabel

Os resultados encontrados diferiram dos encontrados por Zanoni (2000), onde não houve diferenças significativas entre as linhagens Bouaké e Chitralada, mas concondam com os encontrados por Boscolo (2001) e Wagner (2002).

A linhagem Chitralada, quando comparada com as demais linhagens de tilápia do Nilo, apresenta uma característica distinta, que é sua docilidade, facilitando a despesca (KUTTTZA, 2000). Segundo Zimmermann (2000), o peixe tailandês (Chitralada) vem sendo intensamente manipulado há mais de 30 anos, o que pode ser o motivo de sua docilidade. Sendo assim, pode-se inferir, por meio dos resultados observados, que a linhagem Chitralada apresenta um melhor desempenho, nas condições de cultivo intensivo.
A linhagem Supreme introduzida no Brasil em 2002, importada pela Aquabel, é fruto de melhoramento genético e seleção genética, tendo mostrado ser superior às demais linhagens nas duas fases do experimento, apresentando também lotes mais uniformes.

Os resultados encontrados nos tanques foram semelhantes aos na fase inicial e nos viveiros, sendo a linhagem Supreme significativamente superior em todos os parâmetros avaliados, não apresentando diferenças significativas.

A criação em tanque de concreto mostrou-se mais eficiente na produção da linhagem Supreme (Tabela 3). Este fato deve-se provavelmente a que essa linhagem ter maior tolerância ao intenso manejo e alimentar-se exclusivamente de dietas completas. 
Tabela 3 - Valores médios para variáveis de desempenho de peixes mantidos em tanque de concreto das diferentes linhagens de tilápia do Nilo (Oreochromis niloticus) na segunda fase do experimento, de 91 a 134 dias de cultivo.

Table 3 - Average values for fish performance variables, kept in concrete tank, of the different Nile tilapia's strains (Oreochromis niloticus) in the second phase of the experiment, between 91 and 134 days of culture.

\begin{tabular}{|l|l|l|l|l|}
\hline & Comp. padrão & Comp. Total & Peso & Peso do filé \\
\hline CHIM & $16,31 \mathrm{a}$ & $19,91 \mathrm{a}$ & $145,00 \mathrm{~b}$ & $42,93 \mathrm{~b}$ \\
SUP & $19,42 \mathrm{~b}$ & $24,21 \mathrm{~b}$ & $252,00 \mathrm{a}$ & $74,72 \mathrm{a}$ \\
BOKE & $14,10 \mathrm{a}$ & $17,10 \mathrm{a}$ & $92,90 \mathrm{~b}$ & $29,69 \mathrm{~b}$ \\
CHIA & $16,00 \mathrm{a}$ & $19,50 \mathrm{a}$ & $146,00 \mathrm{~b}$ & $42,92 \mathrm{~b}$ \\
\hline
\end{tabular}

${ }^{*} \mathrm{CHIM}=$ Chitralada CODAPAR, SUP= Supreme, BOKE= Bouaké, $\mathrm{CHIA}=$ Chitralada Aquabel

Não houve diferenças significativas entre as linhagens quanto ao rendimento de filé. De acordo com Ribeiro et al. (1998), existe uma correlação positiva entre o tamanho de filé com 0 peso do peixe, não refletindo no seu rendimento de filé. Neste estudo, a linhagem Bouaké apresentou indivíduos menores, filés menores, mas um maior rendimento de filé (Tabela 4).

Tabela 4 - Valores rendimento de filé para as diferentes linhagens de tilápia do Nilo (Oreochromis niloticus) na segunda fase do experimento, criados em viveiros de terra. Table 4 - Filet income values for the different Nile tilapia's strains (Oreochromis niloticus) in the second phase of the experiment, cultivated in land fisheries.

\begin{tabular}{|l|l|l|l|}
\hline & Peso final & Peso do filé & Rendimento de filé (\%) \\
\hline CHIM & $306,82 \mathrm{ab}$ & 92,98 & 30,30 \\
SUP & $344,73 \mathrm{a}$ & 105,49 & 30,60 \\
BOKE & $263,49 \mathrm{~b}$ & 86,88 & 32,97 \\
CHIA & $340,50 \mathrm{a}$ & 104,93 & 30,81 \\
\hline
\end{tabular}

* CHIM= Chitralada CODAPAR, SUP= Supreme, BOKE= Bouaké, CHIA= Chitralada Aquabel 
Para obter melhor rendimento de filé, fatores como a eficiência das máquinas filetadoras e/ ou destreza manual do operador e algumas características intrínsecas à matéria-prima, como a forma anatômica do corpo, tamanho da cabeça, peso dos resíduos (vísceras, pele e nadadeiras), devem ser consideradas (EYO, 1993; CONTRERASGÚZMAN, 1994; RIBEIRO et al., 1998).

Outros estudos são necessários para comprovar superioridade genética da linhagem Supreme.

\section{Conclusões}

A linhagem Supreme mostrou-se superior às demais linhagens nas duas fases de criação, apresentando maior eficiência e comprovando o efeito do melhoramento genético sobre as características produtivas.

\section{Referências}

BENTSEN, H. B.; et al. Genetic improvement of farmed tilapias: growth performance in a complete diallel cross experiment with eight strains of Oreochromisniloticus. Aquaculture, Amstderdam, v. 60, n.1, p. 145-173, 1998.

BOLL, M. G.; SATO, G.; AMARAL JUNIOR, H. A Resultados preliminares de método alternativo de manejo da tilápia, Oreochromis niloticus, no período de inverno em regiões de clima subtropical. In _ : ENCO NTRO DE TECNICOS EM AQÜİCULTTURA, 6., 1995, Ibirubá; ENCONTRO BRASILEIRO DE AQÜICULTURA, 3., 1995, Ibirubá. Anais... Porto Alegre: UFRS, 1995. p. 88-93.

BOSCOLO, W.R.; HAYASHI, C.; SOARES, C.M. Desempenho de machos revertidos de tilápias do nilo (Oreochromisniloticus, L), linhagens tailandesa e comum, nas fases inicial e de crescimento. In: CONGRESO SURAMERICANO DEACUICULTURA, 2., Anais... [s. l. : S. n.], 1999. p.84-90.

BOSCOLO, W. R.; HAYASHI, C.; SOARES, C. M. Desempenho de machos revertidos de tilápias do Nilo (Oreochromis niloticus), linhagens tailandesa e comum, nas fases inicial e de crescimento. Revista Brasileira de Zootecnia, Viçosa, v. 30, n. 5, p. 1391-1396, 2001.
CONTRERAS-GÚZMAN, E.S. Bioquímica de pescados e derivados. Jaboticabal: Funep, 1994.

CYRINO, J. E. P.; CARNEIRO, P. C. F.; BOZANO, G. L N. et al. Desenvolvimento da criação de peixes em tanque-rede: uma análise dos fundamentos, viabilidade e tendências, baseadas em experiências bem sucedidas no Sudeste do Brasil. In: AQÜICULTURA BRASIL98, 1., 1998, Recife. Anais... Recife: SIMBRAQ, 1998. p. 409-433.

EUCLY DES, R. F. Manual de utilização do programa SAEG (Sistemas de Análises Estatísticas e Genéticas). Viçosa: Universidade Federal de Viçosa: Centro de Processamento de Dados, 1983. $59 \mathrm{p}$.

EYO, A.A. Carcass composition and filleting yield of tem species from Kainji Lake.(Proceedings of the FAO Expert consultation of fish technology in Africa). FAO Fish. Rep., Rome, v. 467 (suppl.), p. 173-175, 1993.

FITZSIMMONS, K. Tilapia: the most important aquaculture species of the $21^{\text {st }}$ Century. In TILAPIA AQUACULTURE IN THE $21^{\text {st }}$ CENTURY, 1., 2000b, Rio de Janeiro. Prooceedings... Rio de Janeiro: Panorama da Aqüicultura, 2000. p. 3-8.

HERBINGER, C. M.; DOYLE, R. W. O'REILLY, P. T. Pedigree determination using DNA markers and applications to cultivated salmonid populations.In: WORLD AQUACULTURE SYMPOSIYM, 1997, San Diego, Califórnia. Abstract... 1997. p. 208.

HISDORF, A. W. S. Genética e cultivo de tilápias vermelhas: revisão. Boletim do Instituto de Pesca, São Paulo, v. 22, n. 1, p. 73-84, 1995.

JHINGRAN, V. G.; GOPALAKRISHNAN, V. Catalogue of cultivated aquatic organisms. FAO Fisheries Technical Paper, n. 130, 1974.

KUBTIZA, F. Tilápia: tecnologia e planejamento na produção comercial. Jundiaí: F. Jundiaí, 2000.

LOVSHIN, L L Tilápia farming: a growing wordwide aquaculture industry. In.: SIMPÓ SIO SOBRE MANEJO E NUTRIÇÃO DE PEIXES, 1997, Rio de Janeiro. Anais... Rio de Janeiro: Panorama Aqüicultura, 1997.

LOVSHIN, L L; CYRINO, J. E. P. Status of commercial fresh water fish culture in Brasil. World Aquaculture, Rio de Janeiro, p. 23-38, 1997. 
POPMA, T. J.; LOVSHIN, L. L. Tilápia especial. Panorama da Aqüicultura, Rio de Janeiro, v. 5, n. 27, p. 7-13, 1995.

RIBEIRO, L P.; et al. Efeito do peso e do operador sobre rendimento de filé em tilápia vermelha Oreochromis spp. In : AQÜICULTURA BRASIL'98, 1., 1998, Recife. Anais... Recife: ABRAQ, 1998. v. 2, p. 773-778.

SCHMIDT, A. A. P. Piscicultura: a fonte divertida de proteínas. São Paulo: Ícone, 1998.

THYS, D. F. E. An annotated bibliography of Tilapia (Pisces, Cichlidae). Mus. R. Afr. Cent. Doc. Zool., v. 14, 1969.

TORLONI, C. E. C.; GALل, L. F. Criação de peixes. São Paulo: Nobel, 1984.
WAGNER, P. M. Avaliação de linhagens detilápia do nilo Oreochromis niloticuse em diferentes fases de criação. 2002. 53 f. Dissertação (Mestrado em Produção Animal- Zootecnia)-Universidade Estadual de Maringá, Maringá, 2002.

ZIMMERMANN, S. Observações no crescimento de tilápias nilóticas (Oreochromis niloticus) da linhagem Chitralada em dois sistemas de cultivo em três temperaturas de água. In _: TILAPIA AQUACULTURE IN THE 21 ${ }^{\text {a }}$ CENTURY, 2., 2000, Rio de Janeiro. Proceedings... Rio de Janeiro: Panorama da Aqüicultura, 2000. p. 15-21

Recebido em: 14/03/2005

Aprovado em: 30/06/2005 